\title{
A ESCASSEZ DE ÁGUA NO SERTÃo \\ CENTRAL CEARENSE: POLÍTICAS PÚBLICAS DE CONVÍVIO COM A SECA NO MUNICÍPIO DE QUIXERAMOBIM-CE
}

Eduarda Maria Farias Silva - eduardafariass@ hotmail.com Instituto Federal do Ceará

Guilherme Farias de Oliveira - guilherme.f15@live.com Centro Universitário Católica de Quixadá

Bruna Thalya da Silva - brunaa.thalyaa@gmail.com Instituto Federal do Ceará

Jamille dos Reis Amorim - jamillereisamorim@gmail.com Universidade Católica Dom Bosco 


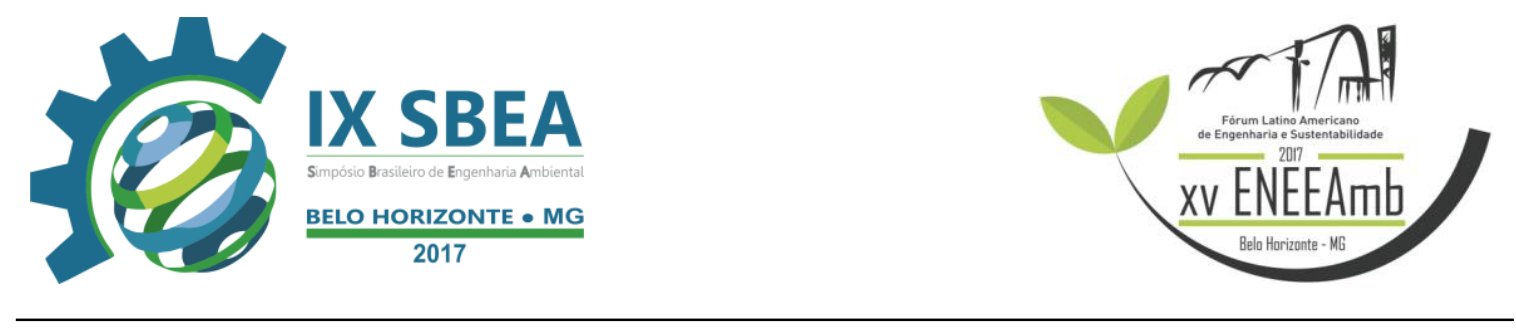

\section{RESUMO}

Os problemas relacionados à falta de água no Sertão Central cearense são constantes, pois existem diversos fatores que contribuem para esse quadro hídrico negativo. Clima quente, altas temperaturas, falta de rios perenes, precipitações pouco frequentes, com má distribuição no tempo e no espaço, são características típicas da região, o que propicia a escassez desse recurso natural.

Partindo desse pressuposto, foram criados, ao longo dos anos, mecanismos que possibilitam o melhor aproveitamento da água, como também, meios de obtê-la que antes eram desconhecidos ou inviáveis. O aperfeiçoamento dessas tecnologias vem tomando grandes proporções e incentivos através de políticas públicas de prevenção e de convívio com a seca. No município de Quixeramobim, esses métodos foram colocados em prática de forma tardia, o município entrou em um colapso hídrico, com isso medidas foram tomadas para auxiliar a população que sofre com os impactos da seca.

Verificou-se a implantação de mecanismos de armazenamento e obtenção de água, através da construção de cisternas e chafarizes, perfuração de poços profundos, e de um sistema de ponteiras aplicado na barragem da cidade, que atualmente está seca. Além de medidas emergenciais como a distribuição de água feita por carros-pipa e a construção de uma adutora, que possibilitou a utilização de água proveniente de outra localidade.

O trabalho teve como finalidade mostrar algumas alternativas de contornar a situação preocupante em que o município encontra-se, e verificar a eficiência dessas políticas através de pesquisa exploratória realizada com populares.

Palavras-chave: Recursos Hídricos, Seca, Políticas Públicas.

\section{INTRODUÇÃO/OBJETIVO}

A água é um bem vital essencial para preservação da vida do planeta Terra e da manutenção da biodiversidade do mesmo. Apesar de ser um recurso renovável, seu consumo exacerbado, coligado ao desperdício e à poluição, vem causando uma exiguidade global. Utilizada como força motriz por diversos segmentos e setores, a água apresenta fundamental importância no desenvolvimento econômico e social do planeta. Segundo a Organização das Nações Unidas (ONU) 70\% da agua potável é utilizada para 


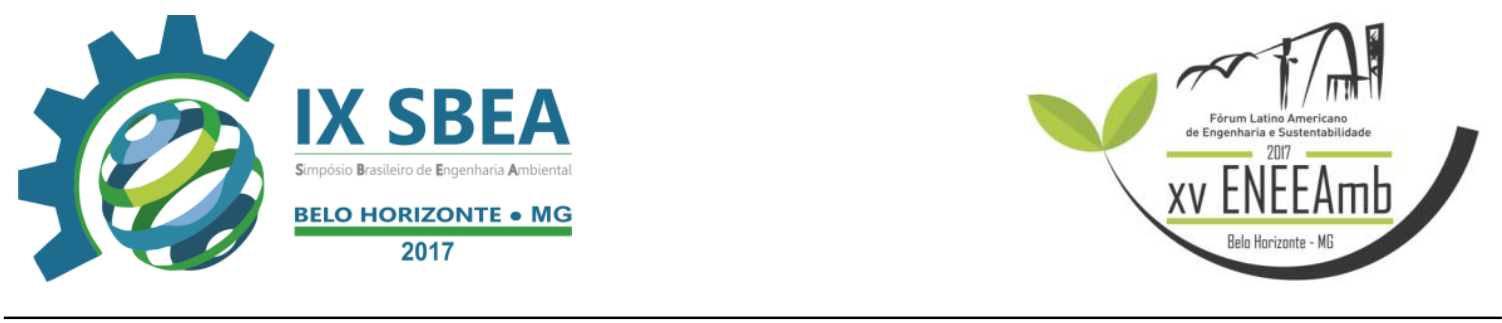

agricultura, $22 \%$ nas indústrias e $8 \%$ para o uso doméstico, confirmando assim, a diversificação no seu uso.

O Brasil é mundialmente conhecido pelo seu potencial hídrico, possuindo o maior aquífero do planeta, e também um dos maiores rios. No entanto no Nordeste brasileiro a situação é invertida, seus reservatórios artificiais, não resistem a extensos períodos de estiagem devido ao seu uso comum, e as elevadas taxas de evaporação que excedem as taxas de precipitação.

No ano de 1915 um fato ocorrido marcou a história do Ceará, naquele ano sucedia a maior seca já registrada, conhecida como "a seca do quinze". Os danos causados foram irreparáveis, muitas vidas foram ceifadas, além da grande migração para regiões com melhores condições de vida. Cem anos após este episódio, em 2015, a situação repete-se, contudo através do desenvolvimento tecnológico, e criação de políticas públicas eficientes de convívio com a seca, as consequências foram mínimas, quando comparadas.

A região do sertão central cearense enfrenta grandes desafios, de ordem social, econômica, política e ambiental, oriundos da grande escassez de água devido à baixa precipitação, ocasionada por fatores climáticos típicos do bioma predominante: a caatinga, após cinco anos consecutivos de seca a população sofre as consequências, necessitando buscar meios de convivência com a mesma.

O município de Quixeramobim, localizado no sertão central cearense, é conhecido como o "coração do Ceará", devido sua localização geográfica central. Possui a maior bacia leiteira do estado, e consegue manter esse quadro mesmo com a realidade da seca, através de outras alternativas. Detém uma população de aproximadamente 77.930 mil habitantes (IBGE, 2010). O município compõe o chamado perímetro da seca, onde os fatores climáticos que proporcionam a escassez de água são acentuados. Daí a preocupação dos autores com o estudos das políticas implantadas no município, que vive atualmente um verdadeiro colapso hídrico.

O presente artigo tem por objetivo, através de revisão bibliográfica, interpretar o conceito de seca diante dos diversos segmentos relacionados. Segundo Campos e Studart (2001), “conceituar seca é a primeira dificuldade que enfrenta quem escreve sobre o tema. 


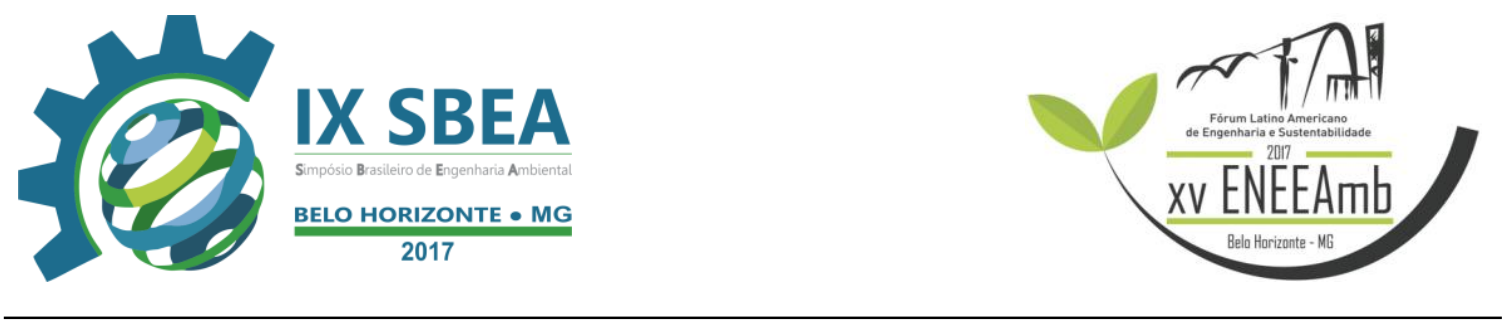

Não há uma definição universal aceita. O conceito varia segundo o ponto de visto do observador". Além de identificar as políticas públicas utilizadas para obtenção e armazenamento de água, e analisar a eficiência destes métodos. Por fim, apresentar os resultados de uma pesquisa exploratória junto a população sobre a eficiência dos métodos utilizados para minimizar os efeitos da seca no município de Quixeramobim-CE.

\section{METODOLOGIA}

O estudo feito é de natureza qualitativa pois está ligado ao levantamento de informações, no intuito de entender e explicar os procedimentos, opinião e percepção dos indivíduos. Quanto aos meios a pesquisa é de campo, pois é aquela empregada com o objetivo de obter informações e conhecimento sobre um problema no qual buscamos uma resposta. Com relação aos fins, a pesquisa é descritiva pois tem por objetivo primordial a descrição e a interpretação da realidade. (SEVERINO, 2007).

Para elaboração do artigo, foi realizada uma pesquisa bibliográfica e exploratória com o intuito de compreender detalhadamente a seca e seus efeitos no decorrer da história, além de detectar as ações desenvolvidas pelos órgãos públicos competentes como o Sistema Autônomo de Água e Esgoto (SAAE) e Secretárias Municipais, no enfrentamento a seca.

Visando verificar os impactos dessas ações no dia-a-dia da população, realizou-se uma entrevista baseada em um questionário pré-elaborado, buscando respostas que evidenciem as causas desse déficit hídrico e constatando, se os métodos utilizados foram aplicados de maneira correta e eficiente.

A pesquisa realizada com moradores do município, ocorreu entre os meses de setembro e outubro de 2016. A coleta de dados foi feita com entrevista estruturada com perguntas abertas. A análise dos dados apurados serão apresentados no trabalho, com o objetivo de expor os resultados colhidos sobre a implantação das políticas públicas de convívio com a seca.

Utilizou-se como forma de obtenção de informações um questionário aplicado à população do município, foram entrevistados ao todo 60 moradores de diversos locais do município, rural e urbano, contendo as seguintes interrogações: 


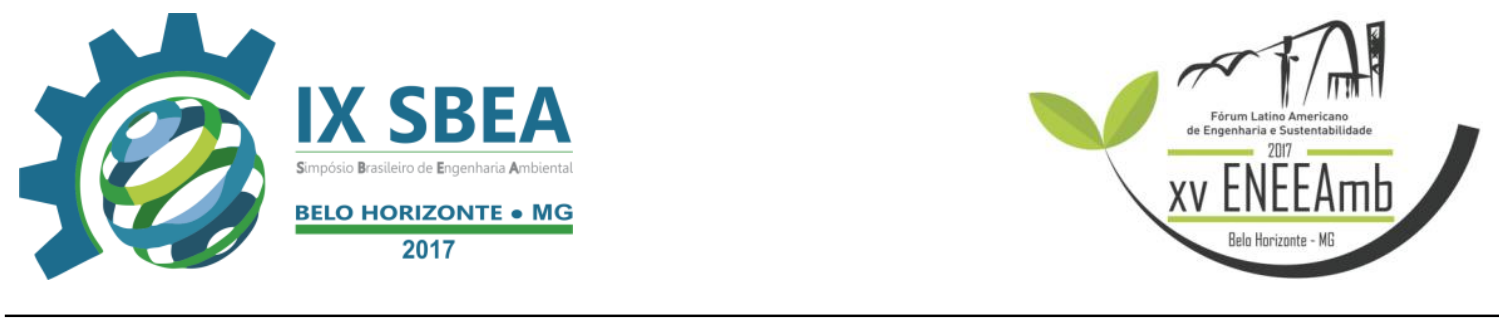

- Reconhece que o munícipio está passando por um intenso período de estiagem?

- Esse período trouxe impactos negativos?

- Você acha que a falta de água poderia ter sido evitada?

- Você fez racionamento de água? De que forma?

- A população influenciou na falta de água?

- O desperdício contribui com a escassez de água?

- Foram implantadas medidas para amenizar os efeitos da seca, pelos órgãos competentes?

- As políticas públicas executadas nesse período foram eficientes?

- Elas deveriam ter sido implantadas há mais tempo?

- A maneira que essas medidas foram implantadas foi eficiente?

Além disso realizou-se uma questionário sócio econômico, com o intuito de identificar idade e renda familiar do público alvo da pesquisa.

\section{RESULTADOS E DISCUSSÃO}

Os resultados do questionário estão dispostos nos gráficos a seguir:

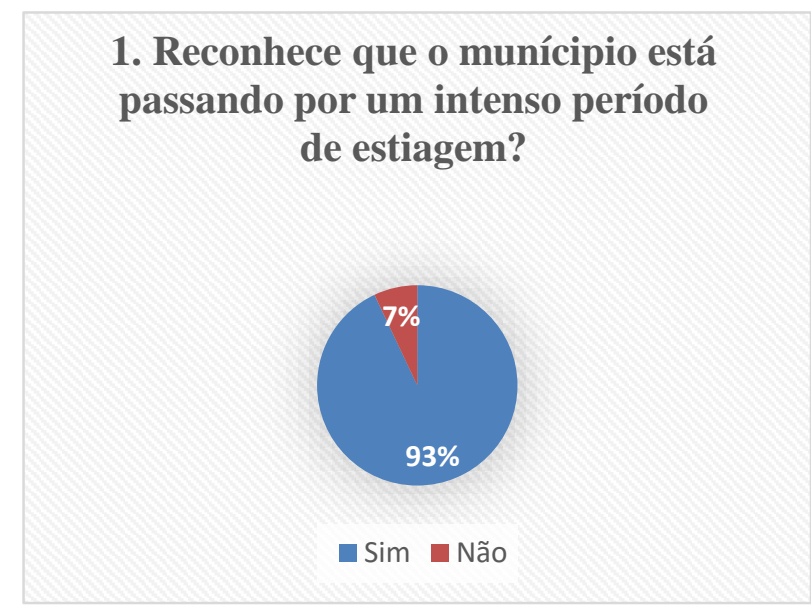

Fonte: próprio autor

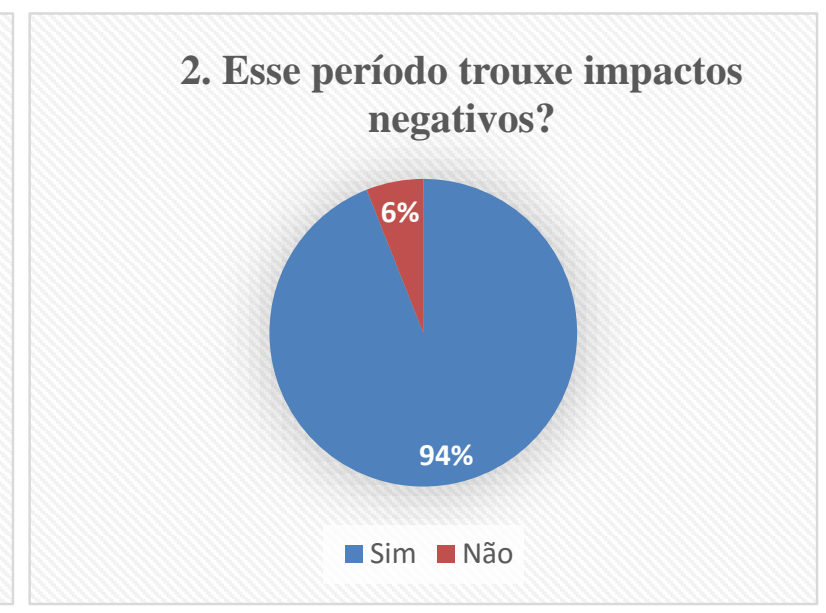

Fonte: próprio autor 


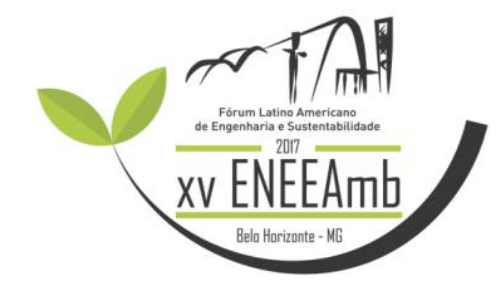

3. Você acha que a falta de água poderia ter sido evitada?

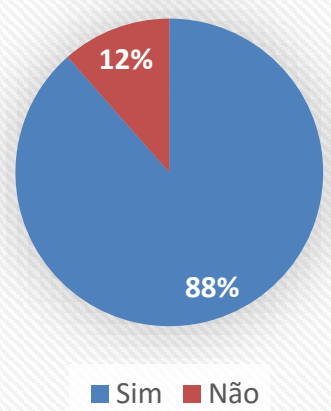

Fonte: próprio autor

5. A população influenciou na falta de água?

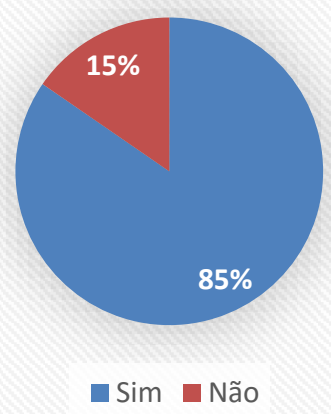

Fonte: próprio autor

7. Foram implantadas medidas para amenizar os efeitos da seca, pelos órgãos competentes?

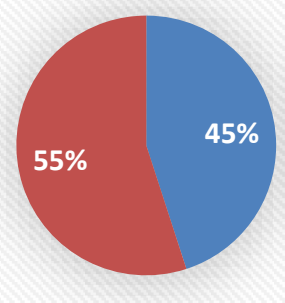

ロ Sim — Não

Fonte: próprio autor

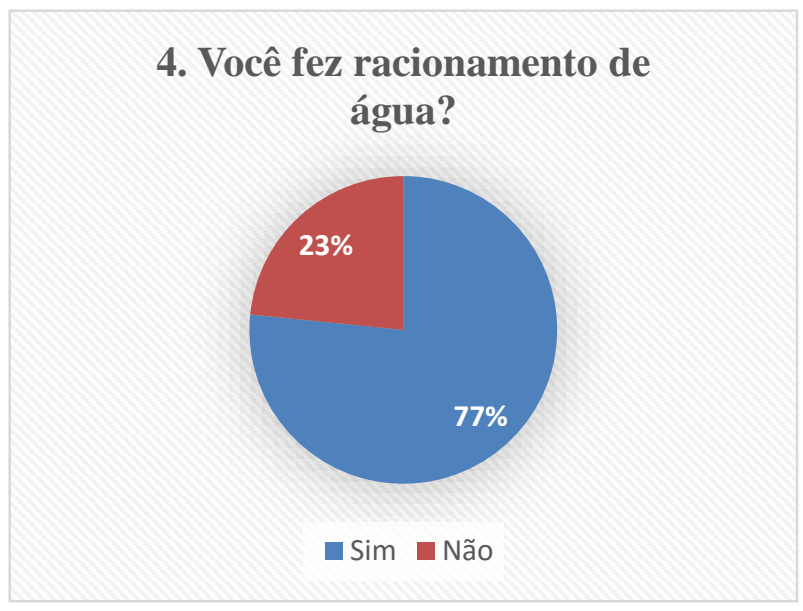

Fonte: próprio autor

\section{O desperdício contribui com a escassez de água?}

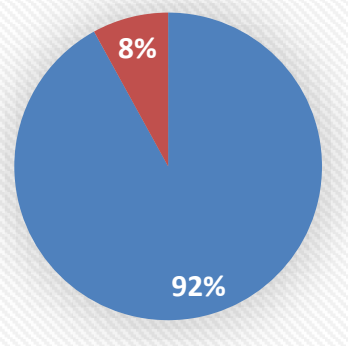

— Sim não

Fonte: próprio autor

\section{As políticas públicas executadas} nesse período foram eficientes?

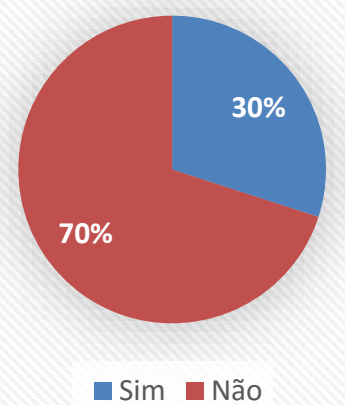

Fonte: próprio autor 


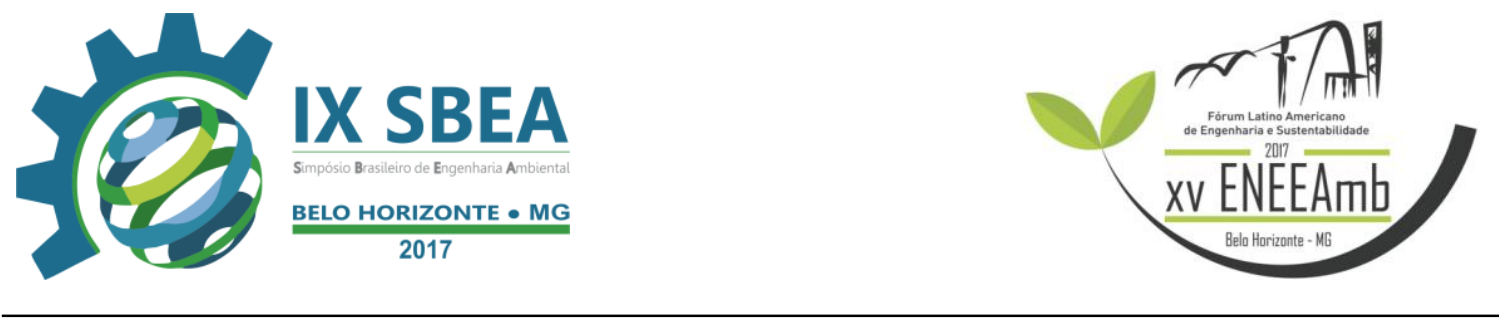

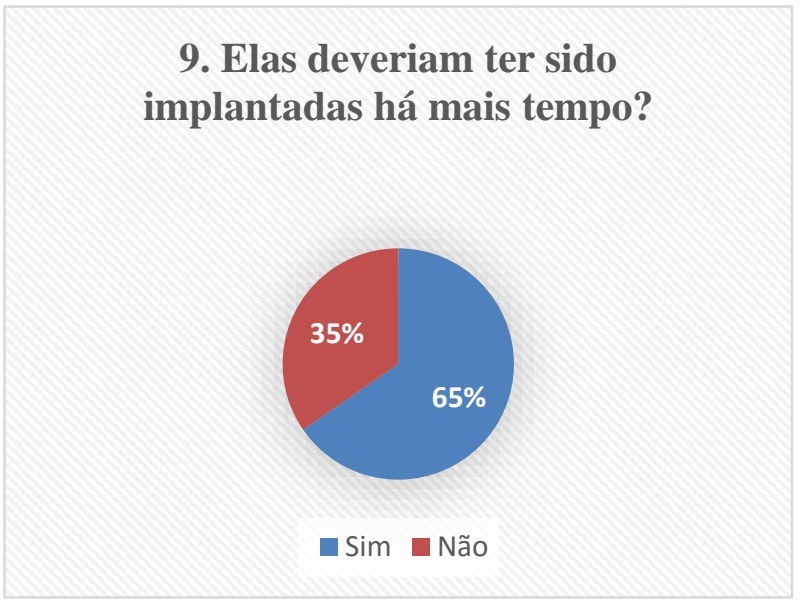

Fonte: próprio autor
10. A maneira que essas medidas foram implantadas foi eficiente?

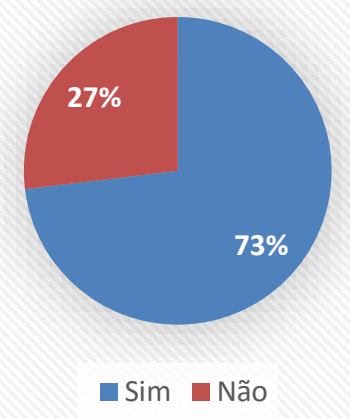

Diante do exposto é perceptível que a maioria da população tem consciência de que o município passa por um período de estiagem intenso, e que esse fato afeta suas atividades diárias, e causa danos sociais, econômicos e ambientais. Contudo, essa consciência não é comum a todos, uma parcela reduzida ainda não percebe os impactos gerados (como podemos perceber no gráfico 2). No gráfico 4, $77 \%$ dos entrevistados alegam ter feito racionamento de água, e esse percentual não é observado no dia a dia, é rotineiro nos depararmos com situações de desperdício de água. A educação ambiental torna-se uma forte aliada na tentativa de mudança dos hábitos das pessoas. É ciente que o desperdício aliado as condições favoráveis a escassez gera diminuição do nível d'água de mananciais, notou-se que parte dos entrevistados consideram que as políticas públicas implantadas ocorreram tardiamente contribuindo assim para o agravamento da situação hídrica do município (ver no gráfico 9).

\section{POLÍTICAS PÚBLICAS}

Entende-se por políticas públicas o conjuntos de programas, ações e atividades desenvolvidas pelo Estado diretamente ou indiretamente, com a participação de entes públicos ou privados, que visam assegurar determinado direito de cidadania, de forma difusa ou para determinado seguimento social, cultural, étnico ou econômico. Através de pesquisa exploratória realizada em campo, e visitas aos órgãos municipais competentes (SAAE, Secretária de Infra Estrutura) verificou-se a implantação de medidas tidas como emergenciais, na tentativa de solucionar a falta de água. 


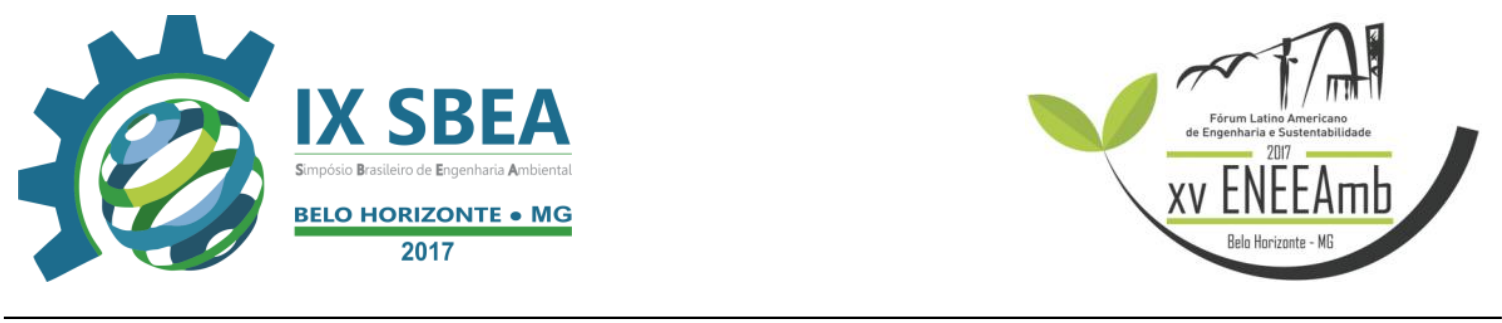

A concessionária responsável pelo fornecimento de água no município (SAAE) realizou racionamento de água, interrompendo o abastecimento em determinados dias, intercalados entre regiões do município. A problemática é que esse racionamento só efetivou-se após os índices de água dos rios, que alimentam a cidade estarem em níveis alarmantes. A perfuração de poços profundos ocorreu com o incentivo do governo federal e municipal, além da iniciativa privada, foram perfurados no total cerca de 100 poços. Mesmo com um número elevado de poços perfurados a vazão conjunta ainda não era suficiente para as necessidades básicas da população, então, concomitante a isso, foram implantados chafarizes, distribuídos entre os bairros de maior carência.

Surgiu então a ideia de utilizar uma tecnologia nova na barragem do município, que estava seca. Implementou-se um sistema de ponteiras (são canos revestidos por uma tela, tem terminação cônica e são cravadas no terreno, possibilitando a retirada de água com bombas de sucção) que permitia através de máquinas a retirada de água existente no subsolo daquele manancial. Os resultados foram satisfatórios e a vazão obtido ali foi aproximadamente $50 \mathrm{mil}$ litros/hora. Ainda houveram medidas emergenciais, como a utilização de carros pipa, símbolo das regiões de seca, marcado através da história pela limitação dos recursos hídricos, o que gera forte receio por parte principalmente das classes menos favorecidas.

Aliadas a todos as medidas citadas, o governo federal realizou a entrega de uma adutora responsável por captar água do Açude Pedras Brancas, localizado no município vizinho, Quixadá-CE. O abastecimento do município de Quixeramobim-CE deu-se então por meio dessas medidas, tidas como políticas públicas, que resolveram pelo menos momentaneamente, os problemas com a escassez dos recursos hídricos. 


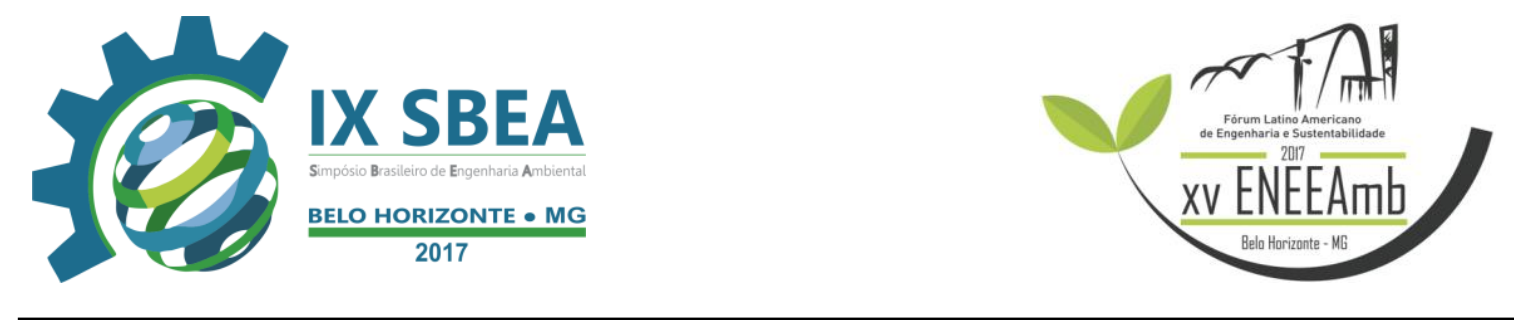

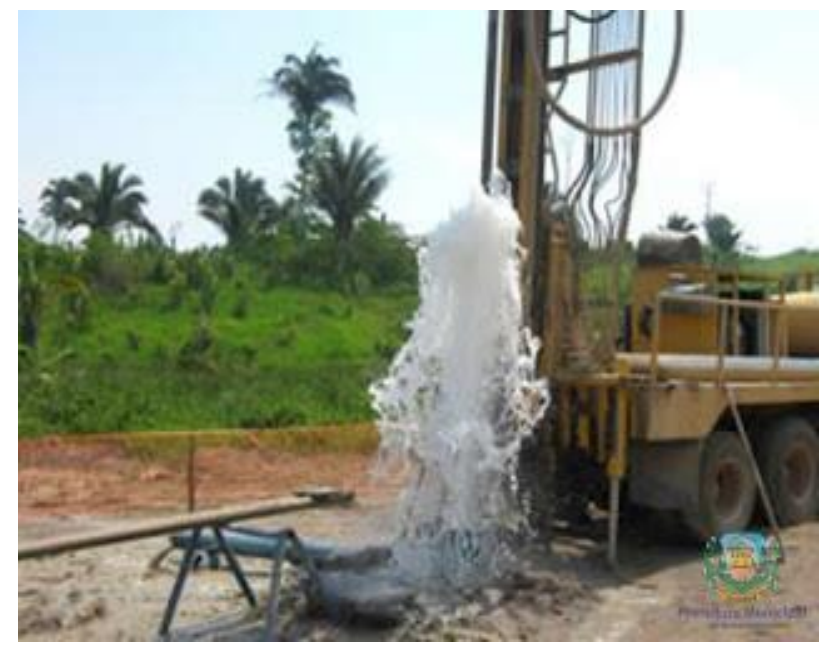

Perfuração de poços profundos Fonte: Prefeitura Municipal de Quixeramobim

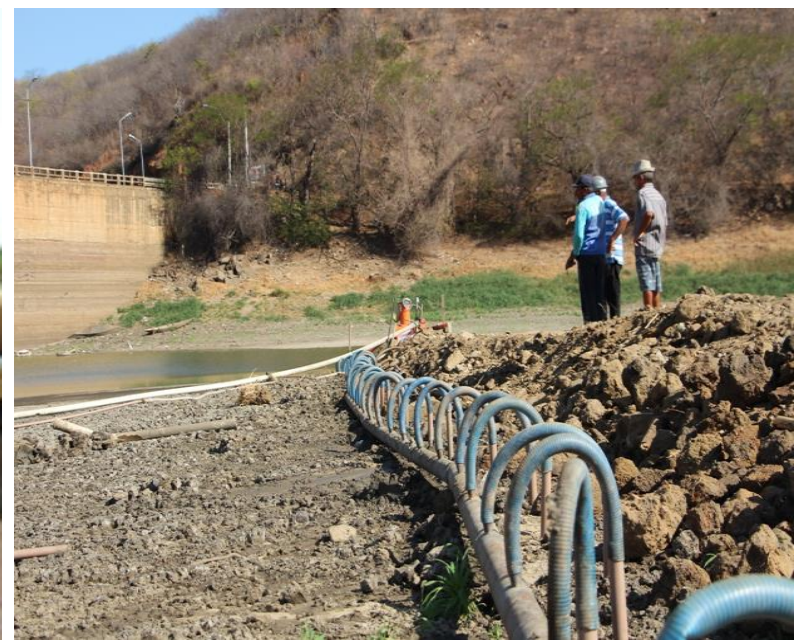

Sistema de ponteiras na barragem Fonte: Prefeitura Municipal de Quixeramobim

\section{CONCLUSÕES/RECOMENDAÇÕES}

O convívio com a seca é hoje um dos grandes desafios a ser enfrentado, suas consequências ao longo da história deixou marcas acentuadas que refletem no dia-a-dia das pessoas. Com os avanços tecnológicos no ramo da ciência, as políticas públicas surgem como alternativa para minimizar os impactos causados, permitindo que a população possa superar as consequências trazidas pela seca.

Com o crescimento populacional e os mais diversos avanços nos setores da sociedade a busca por este bem vital só aumentará e assim gerará escassez se não for gerenciado de forma racional, contudo se faz necessário aliar ações de convívio com a seca com a conscientização por parte da população que ainda é indiferente diante da situação em que vive o município.

Conclui-se que as políticas públicas implantadas foram de extrema importância para a preservação da qualidade de vida das pessoas, e manutenção de suas atividades básicas. Entretanto, é de fundamental importância a implementação de planos de gerenciamentos de recursos hídricos, que levem em consideração o quadro desfavorável que a região apresenta. Somente assim, por meio de efetivas políticas e consciência ambiental por parte da população, que esse problema poderá ser controlado e a probabilidade de ocorrer colapsos hídricos, será vigorosamente minimizado. 


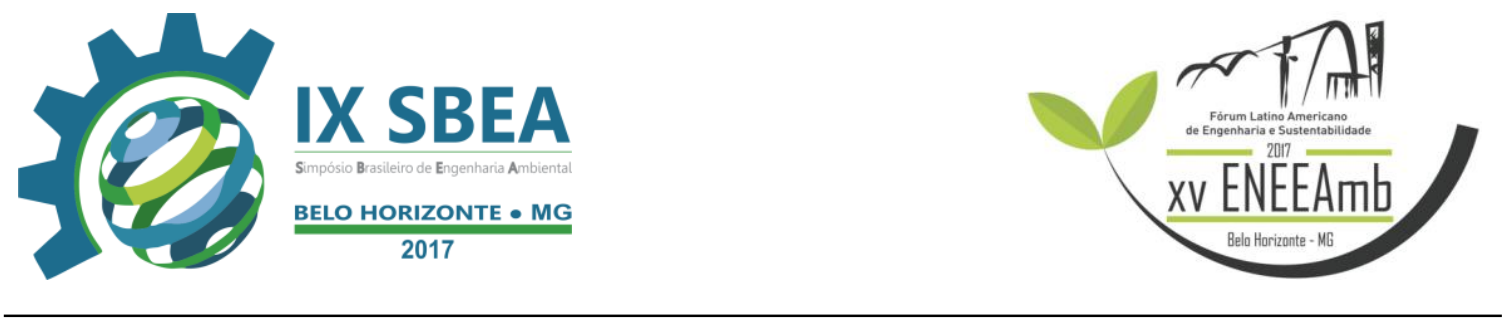

\section{REFERÊNCIAS BIBLIOGRÁFICAS}

ASSEMBLEIA LEGISLATIVA DO ESTADO DO CEARÁ. Cenário atual dos recursos hídricos do Ceará. Fortaleza: INESP, 2008.

CAMPOS, J.N.B., STUDART, T.M.C. e LIMA, H.C. (1994). Secas no Nordeste Brasileiro diante de um Cenário de Mudanças Climáticas. Associação Brasileira de Recursos Hídricos. Anais do II Simpósio de Recursos Hídricos do Nordeste, v.1.p.20, Fortaleza, Ceará.

CAMPOS, J. N. B.; STUDART, T. M. C. Secas no Nordeste do Brasil: origens, causas e soluções. In: INTER-AMERICAN DIALOGUE ON WATER MANAGEMENT, 4, 2001, Foz do Iguaçu. Anais... Foz do Iguaçu: Associação Brasileira de Recursos Hídricos, 2001.

GIL, A. C. Como elaborar projetos de pesquisa. [s.l.: s.n.], 1991. p. 45.

IBGE. Instituto Brasileiro de Geografia e Estatística. Dados cidades. Disponível em: http://cidades.ibge.gov.br/xtras/perfil.php?codmun=231140. Acesso em: 25 nov.2016.

SECRETARIA DE RECURSOS HÍDRICOS (1999). Revista Interágua $\mathrm{n}^{\circ} 2$. Disponível em: www.srh.gov.br. Acesso em: 23 nov.2016.

SEVERINO, Antônio Joaquim. Metodologia do trabalho científico.-23º.ed.rev e atual.- São Paulo: Cortez, 2007.

ONU. Organização das Nações Unidas. A ONU e a água. Disponível em: https://nacoesunidas.org/acao/agua/. Acesso em: 16 nov.2016. 